\title{
A ausência-presença performática do autor: Ricardo Lísias e sua Vista particular
}

\author{
Anderson Bastos Martins* \\ Reinaldo Ziviani da Silva**
}

\begin{abstract}
RESUMO: Em sua obra, Ricardo Lísias se notabilizou pela escritura de auto ficções polêmicas pelas ambiguidades envolvidas nesse processo literário. Em A vista particular (Alfaguara, 2016), depara-se com um enredo cujo protagonista é um artista que também se utiliza de mecanismos da arte contemporânea antimimética. As ações extremas e mesmo surreais dessa personagem podem ser analisadas como meio de entendimento da proposta de Lísias em suas obras, bem como o autor se inscreve performaticamente como um personagem de si mesmo, tornando sua vida pública indistinta da sua obra.
\end{abstract}

Palavras-chave: literatura; arte contemporânea; Ricardo Lísias; autoria; auto ficção; performance.

\section{Introdução}

$\mathrm{O}$ texto que se apresenta tem por base temática parte significativa de minha pesquisa de mestrado - ainda em desenvolvimento. De uma forma geral, o estudo pretende demonstrar, por meio da análise da obra de Ricardo Lísias, em especial A vista particular, como esse autor se estabeleceu como um personagem de si. Extrapolando inclusive os limites do livro. Paralelamente discutimos de que forma Lísias se utiliza das ambiguidades ficção e vida, próprias da arte contemporânea para evidenciar a relação problemática que setores como a justiça, a imprensa e a política assumiram com esses artifícios atualmente. Isso porque julgo que o fenômeno da pós-verdade, tão propalado em 2016, apesar de seguir uma lógica já antiga se configura em um momento singular pela relação comunicativa em redes em que nos encontramos. Um cenário de criação da realidade por meio de "simulação" (BAUDRILLARD, 1991). Neste artigo, contudo, irei me deter no aspecto da autoria de uma forma menos usual por considerar que Lísias se coloca como uma auto personagem, dentro e fora do texto literário. Nessa ação, suscita a discussão da presença e relevância do elemento autor para a arte contemporânea antimimética. Em correlação com esse tema de legitimação da arte e performatização da autoria está a simulação como mecanismo de estabelecimento de sentidos há pouco mencionado. A obra, lançada também em 2016 se constitui uma dentre muitas narrativas em que o autor se elabora e se ressignifica como um artista contemporâneo, cujo principal material de criação são as ambiguidades entre ficção e fato. Dessa forma, também utilizo, a título de comparação, outro caso de performance artística, proposto por Yuri Firmeza, que discute a autoria e o sistema de artes contemporâneo.

\section{A Vista particular e o tensionamento da autoria}

A narrativa em foco, A vista particular, pode ser encarada, dentre outras perspectivas, como uma discussão da relação antimimética da arte contemporânea e a maneira homóloga com que têm atuado os meios de comunicação na atualidade. Salientando que, para Rancière, o que diferencia a arte da modernidade até os nossos dias é uma ruptura com a necessidade de representação. Para o teórico francês vivemos em um "regime estético" das artes, o que significa a abolição de regras, gêneros, estilos ou temas específicos na arte, ainda que a identifique de forma singularizada. "Mas, ao fazê-lo, ele implode a barreira mimética que distinguia as maneiras de fazer arte das outras maneiras de fazer e separava suas regras da ordem das ocupações sociais" (RANCIÈRE, 2009, p. 34).

Embora a obra em questão não seja formalmente uma auto ficção, ela aponta para a relação de autoria e do artista moderno e contemporâneo, tal qual encaro Lísias, 
em um diálogo muito próximo com a auto ficionalidade. A trajetória do protagonista, José de Arariboia, por exemplo, insinua a ideia da construção e desconstrução da subjetividade, na forma de personagem e mito, pela atuação do autor (artista). E, por outro lado, observa-se o papel da subjetividade na recepção agindo da mesma forma na construção e desconstrução dos sentidos. De alguma maneira, podemos parear, ainda que imprecisamente, o caminho traçado por José de Arariboia, sua elaboração enquanto artista e os processos também performáticos de Lísias na sua auto elaboração, enquanto um personagem de si em espaços internos e externos aos do texto das obras.

$\mathrm{Na}$ narrativa, Arariboia apresenta uma arte que rompe em absoluto com a ideia de representação, na medida em que realoca as cenas, fatos e sujeitos da favela do Pavão-Pavãozinho, no Rio de Janeiro, convertendo as situações factuais em instalações. A exposição Comunidade Brava: Turismo Brasil vai migrando e o morro em sua quase integralidade em um movimento surreal. Primeiro a favela se desloca para Inhotim e posteriormente para a Bienal de Veneza, intensificando a presença de performances do artista. Uma delas deve ser destacada e diz respeito à relação entre moradores da favela e a polícia em suas ações repressoras - o que pode ser verificada na performance intitulada "Pedreiro Amarildo é preso, torturado e desaparece no interior de uma Unidade de Polícia Pacificadora" (LÍSIAS, 2016a, p. 96). Em um momento anterior do enredo, o caso do menino negro morto dentro da obra - sendo parte dela - é comparado ao caso do garoto sírio Aylan Kurdi, morto na tentativa de travessia de barco entre a Turquia e a Grécia ${ }^{1}$.

Os principais canais de televisão do mundo só falam da morte do Menino Negro dentro da exposição Comunidade brava: turismo Brasil. Na internet, é como se nada mais estivesse acontecendo. A repercussão é a mesma do afogamento do garoto sírio Ailan, hoje esquecido, na Grécia. (LÍSIAS, 2016a, p. 94)

A maneira como as performances são tratadas induzem a inferir que a construção dos fatos e também das subjetividades na vida pública, seguem um processo ficcional como na arte. Da mesma maneira, os sujeitos que são notabilizados na mídia se constroem como personagens dos meios de comunicação e do senso comum através de narrativas que operam de maneiras semelhantes às das artes. É patente a crítica à forma como essas notícias criam, muitas das vezes, espetáculos que têm por intenção comover e distrair, e o pouco comprometimento com a informação e o debate legítimo. Em contrapartida, a relação de criação das próprias narrativas que compõem o factual se perfaz, e cada vez mais, pela lógica da simulação. Nesse sentido, é impossível estabelecer a história real de um sujeito, a não ser se a limitarmos a um contexto específico que atende a uma configuração e foco particulares.

Seguindo nessa mesma linha de raciocínio, percebe-se que em A vista particular, em diversos momentos, surge alguma personagem que se constitui uma personalidade conhecida nos campos da comunicação, artes, literatura, política. O enredo é regularmente pontuado por essas figuras que formam uma lista relativamente extensa das quais podemos citar o filósofo francês Georges Didi-Huberman, os críticos de arte Rodrigo Naves e Silas Martí, os empresários Assis Chateaubriand e Ciccillo Matarazzo, a psicanalista Maria Rita Khel, o filósofo Vladimir Safátle, o pesquisador e curador Paulo Herkenhoff, os jornalistas Merval Pereira e Ilze Scamparini e o arquiteto Santiago Calatrava. Não apenas figuras históricas como Chateaubriand podem ser reconhecidas como personagens mesmo fora da cena do texto, vez que são sujeitos que nos aparecem regularmente na imprensa televisiva, ou na internet. $\mathrm{O}$ já citado pedreiro Amarildo e o menino Aylan, ainda que em outro tempo fossem figuras anônimas, se converteram 
também em personalidades, mesmo que de forma trágica. Assim, todo esse rol de figuras públicas se apresenta como uma constatação de que, enquanto indivíduos ilustres, se estabelecem como performatizações que se instauram de maneira muito similar à de personagens que compõem uma trama literária. Essa estratégia nos parece mais acertada e ousada que a de outros ficcionistas brasileiros atuais que optam, por exemplo, por construir personagens com passagens curtas no enredo, mas que têm o seu status de correspondência com a fatualidade efetuado de forma meramente referencial, dentro da trama.

De qualquer maneira, o que fica manifesto é o processo de elaboração da subjetividade, sendo que podemos estabelecer uma certa diferenciação no caso do artista, já que ele participa, em alguma medida, de forma mais ativa na criação e celebrização de si. O José de Arariboia que vai se construindo e descontruindo ao longo da trama, se perfaz através das obras de arte que vai produzindo ao longo dessa trajetória. É certo também dizer que a participação da recepção dessas criações impõe características que vão definir esse sujeito. Não se trata, portanto, de mera imposição do artista e nem mesmo do público, mas numa interação que se traduz bem pelo conceito de "auto ficção como performance" (KLINGER, 2012). O artista se instaura como auto personagem, ou como um ator que encena seu próprio papel construído em tempo presente.

Diana Klinger ao trabalhar a auto ficção não a restringe à literatura, mas se concentra no elemento autor. Considero possível ampliar o conceito de auto ficção para toda a espécie de narrativa artística em que o autor se coloca como uma figura pública que, em seu processo de criação e interação, desenvolve uma espécie de personagem de si mesmo. Essa também é a opinião de Klinger, que não encara a estratégia auto ficcional como uma referencialização à vida do escritor, mas uma forma de operar artisticamente que o elabora enquanto um mito. "Confundindo as noções de verdade e ilusão, o autor destrói a capacidade do leitor de 'cessar de descrer'. Assim, o que interessa na auto ficção, não é a relação do texto com a vida do autor, e sim o emprego do texto na criação de um "mito do escritor" (KLINGER, 2012, p. 45).

A vista particular, ainda que não se proponha a ser uma obra auto ficcional, atinge essa temática metaficcionalmente ao narrar a trajetória de um artista que acaba se elaborando enquanto mito no espaço entre criação e recepção de sua arte. É a partir de um emblemático happening que Arariboia passa a ser encarado como figura mitificada e isso se faz perceptível, por exemplo, na forma como esse público espectador age e reage dentro do happening, seguindo e imitando Arariboia como se ele assumisse a condição arquetípica do herói.

\footnotetext{
Na esquina da Francisco Sá com a Nossa Senhora de Copacabana, o grupo é bem numeroso. A maioria dos seguidores de Arariboia é jovem, embora aqui e ali a gente encontre um adulto bem alegre, saltitando como se tivesse vinte anos de novo. Os idosos ficam parados na calçada mesmo. É animador vê-los erguendo os braços enquanto aplaudem a coreografia do nosso herói. Quem não tem os cabelos longos faz o que pode com o pescoço mesmo. (LÍSIAS, 2016a, p. 23)
}

A partir desse instante, Arariboia será identificado pelo narrador várias vezes cerca de doze - como o "nosso herói". Evidentemente Arariboia não se justapõe à condição dos heróis das epopeias gregas e nem mesmo a um conceito moderno de herói. Ainda assim, nesse momento é a condição mitificada por ele assumida como produto de um evento que se aproxima em muito do conceito de "simulação" (BAUDRILLARD, 1991). Mesmo porque, não existe uma ideia de referencialidade. Podemos mesmo 
aproximar Arariboia de outras personagens como o próprio Lísias pelo aspecto da forma de criação e também por essa ideia do autor e artista enquanto um mito. Mas, não existe uma tentativa de imitação. Percebe-se uma ruptura com a mímesis clássica que pode ser reafirmada naquilo que propõe Klinger para entender a auto ficção na elaboração do elemento autor.

\begin{abstract}
A auto ficção participa da criação do mito do escritor, uma figura que se situa no interstício entre a "mentira" e a "confissão". A noção do relato como criação da subjetividade, a partir de uma manifesta ambivalência a respeito de uma verdade prévia ao texto, permite pensar, como veremos a seguir, a auto ficção como uma performance do autor. (KLINGER, 2012, p. 46).
\end{abstract}

Estendo essa noção às criações artísticas não discursivas em sua origem, por considerar que a relação de Arariboia com a recepção da crítica, bem como do público médio, repercute em outros eventos e mesmos discursos que corporificam um personagem que é simultaneamente um autor. Por outro lado, demonstra uma postura evasiva e ao mesmo tempo, dúbia. Se o artista se expõe de forma radical, inclusive mostrando o corpo nu em sua apresentação na Praia de Copacabana, se esquiva, ou não demonstra nenhum interesse em divulgar possíveis pensamentos e conceitos que norteiam a sua arte, ou mesmo sua vida. Acompanhando a evolução de suas ações, parece existir uma ideia paradoxal de desaparecimento do artista, simultaneamente a uma maior presença de sua figura no ideário do público receptor das obras. Essa ideia de desaparecimento pode ser, inclusive, inferida pelas transformações no nome da personagem que vai se decompondo e diminuindo. De José de Arariboia passa a ser Arariboia, posteriormente Arariba e por fim, Arara. Ao mesmo tempo, seu reconhecimento é cada vez maior. Durante as polêmicas de sua exposição no Museu do Amanhã o impacto de sua obra é comparado ao da de Leonardo da Vinci: "A discussão sobre seu trabalho atingiu um novo patamar. Alguns analistas afirmam que nunca uma obra de arte teve tanta repercussão. Talvez a Mona Lisa" (LÍSIAS, 2016a, p. 94). E já no final da narrativa, ainda mais idolatrado, em sua nova exposição na Guggenheim, Arara não parece estar no prédio, mas ao mesmo tempo está, na percepção do público: "Por aqui, Arara não circulou, mas há boatos de que ele está no prédio. Parece que veio do Brasil em um transatlântico fretado, já que não usa avião de forma alguma. Ao menos é o que o jornalista do New York Times apurou" (LÍSIAS, 2016a, p. 126). Essa presença ausente é a mesma de que trata Klinger ao figurar o autor enquanto um mito, ou, a auto ficção como uma performance.

\title{
A invasão do artista inventado e a invenção performática da realidade
}

Seguindo essa ideia de a arte ser usada como ferramenta para discutir a conformação do autor, enquanto um elemento mítico, é relevante apontarmos um experimento, no mínimo instigante do artista plástico, radicado em Fortaleza, Yuri Firmeza. No início de 2006, Firmeza apresentou uma exposição que não tinha a autoria relacionada com o seu nome, no Instituto Dragão do Mar de Fortaleza. Melhor dizendo, a exposição seria composta pela obra de um artista japonês que, por sua vez, era criação ficcional do próprio Firmeza. Sob o nome de Souzousareta Geijutsuka - com o significado oculto de "artista inventado" - ganhou vida e renome instantâneos por meio de matérias dos dois principais jornais do estado do Ceará - Diário do Nordeste e $O$ Povo, que não se deram ao trabalho de conferir a tradução do nome e nem mesmo o currículo do artista.

Em artigo, Nardélia Martins, recapitula o processo mencionado, sendo que Firmeza "foi convidado pelo Diretor do Museu de Arte Contemporânea na época, 
Ricardo Resende, para participar do projeto 'Artista Invasor', que já havia levado três outros artistas cearenses em anos anteriores a expor suas criações nos espaços do museu" (MARTINS, 2011, p. 409). Ocorre que Firmeza apresentou um projeto performático ainda mais ousado e polêmico em que a performance se construiu, em sua maior parcela, fora do espaço do museu. Como relata Martins, a divulgação e a criação do artista, se fez principalmente através de releases enviados a esses dois principais jornais citados, contendo a proposta da obra e a trajetória do artista fictício. Como Souzousareta Geijutsuka não falava outra língua a não ser o japonês, a comunicação com a imprensa foi intermediada por uma assessora, Ana Monteja - também fictícia e pela qual respondia, na verdade, a então namorada de Firmeza, principalmente através de e-mail.

Guiando-se pelos ditos releases recebidos, o Diário do Nordeste apresentou em seu Caderno 3, do dia 10 de janeiro de 2006, matéria intitulada "Arte, natureza e tecnologia" em que descreve Souzousareta Geijutsuka como célebre artista contemporâneo que já havia realizado exposições em cidades como Tóquio, Nova York, Berlim e São Paulo. O "artista japonês" ironicamente sugeria que a grande influência em sua criação - que ele nomeava por "arte eletrônica" - seria o pintor e escultor francês Marcel Duchamp - um dos responsáveis pela instauração dos primeiros questionamentos sobre o sistema das artes e o valor estético e simbólico das obras.

\footnotetext{
Para o artista japonês, a arte eletrônica adquire uma importância fundamental, a partir do momento em que a tecnologia está presente em cada momento de nossas vidas - do mais banal, ao mais grandioso. Apesar disso, Souzousareta considera que as linguagens artísticas eletrônicas ainda são marginalizadas pela concepção mais tradicional de "história da arte". (MOURA, 2006)
}

A matéria é acompanhada de entrevista, também realizada via e-mail, em que o artista fictício responde a questões sobre o que seria sua "arte eletrônica", o cenário das artes no mundo e mostra um conhecimento surpreendente sobre o Brasil. Conhecida a ficcionalidade das falas, o referido diálogo transcrito ganha um tom irônico com um exemplar desfecho em que Souzousareta se utiliza do termo simulacro para descrever a proposta de sua exposição sintetizando-a a pedido do entrevistador.

Essa exposição tem várias facetas, justamente para poder lidar com vários problemas. Tudo está integrado a um exercício do simulacro, cujo objetivo é retirar os hábitos de seu estado de evidência. Inclusive hábitos estéticos, do tipo "Por que gostamos de arte?". É preciso ver a exposição. (MOURA, 2006)

Em artigo, intitulado "Performance na contemporaneidade", a respeito das estratégias atuais assumidas pela arte performática, o artista e pesquisador Yiftah Peled observa, com efeito, no trabalho de Firmeza "uma relação duchampiana ao ficcionalizar um personagem (como no trabalho Rose Sélavy, de 1920), e, ao mesmo tempo, discursiva, atrelada ao conceito de performatividade de J. L. Austin" (PELED, 2012, p. 57). O processo da produção da performance conceitualmente e sua execução são brevemente relatados por Peled. É relevante mencionar que Firmeza não queria, a princípio, que seu nome fosse vinculado ao projeto. Como informa o próprio Firmeza, o Museu não aceitou, mas optou por contornar a situação propondo que "fosse divulgada a minha exposição e posteriormente eu esclareceria que se tratava de uma curadoria de um artista japonês" (FIRMEZA apud PELED, 2012, p. 57). Assim, a divulgação através de uma assessoria de imprensa também fictícia foi uma forma de resguardar o Museu de acusações de disseminação de informações falsas. Após as publicações das matérias que 
cumpriram papel de composição da obra e do artista ficcional e ao mesmo tempo, da divulgação, foi comunicado à imprensa o verdadeiro teor da obra. Os títulos das publicações nos dias subsequentes, nos mesmos veículos, expressam a indignação dos jornalistas por se sentirem enganados. Citemos alguns exemplos: "Exposição factóide compromete Instituto Dragão do Mar" (Diário do Nordeste) e "Arte e molecagem" (Jornal O Povo), sendo que as duas publicações datam de 11 de janeiro de 2006, um dia após a revelação.

Evidencia-se, de fato, a vinculação do evento com a proposta da arte contemporânea cujo expoente é Duchamp. A própria fala de Souzousareta Geijutsuka na citada entrevista ao Diário do Nordeste denuncia isto na ideia do questionamento do motivo pelo qual gostamos de arte, a ideia da dissociação da estética e do valor simbólico volatilizado nos discursos como os dos veículos de comunicação e a consequente sedução exercida pelo jornalismo. Essa problematização é uma das funções precípuas que assume a arte contemporânea. Em debate realizado pelo Centro Dragão do Mar, à época do ocorrido, Firmeza declarou: "Os jornais de hoje (quarta-feira) confirmam o descaso, comprovam que não têm seriedade. Seduzi os jornais do mesmo modo que eles seduzem o público. A obra é uma situação." (FIRMEZA, 2006). E em outro trecho diz também que objetivava "discutir o museu como espaço de conservação simbólica e outras questões que não sejam propriamente estéticas (FIRMEZA, 2006).

\section{Ricardo Lísias e o ato criador de si: o mito do artista contemporâneo}

Se a arte contemporânea assume como propósito seu autoquestionamento, bem como o da valoração simbólica em outras instâncias discursivas, podemos ressaltar também que a questão da fabricação do autor, enquanto personagem e sua relação com a autoridade é um dos pontos centrais desse cenário. O enredo de A vista particular, sugere um conceito de autoria que é também uma função ou elemento extratextual. Da mesma maneira como Klinger observa que a auto ficção, dentre outros processos de criação artística contemporânea, busca a problematização da autoria na "forma de questionamento do recalque modernista do sujeito" (KLINGER, 2012, p. 30). Ainda que se questione a ideia de representação, na conformação de uma fatualidade, sempre resta a sombra de um agente, ainda que ele seja concomitantemente espectador, ator e personagem.

A vista particular, ao questionar o sistema de artes e sua validação, através da ideia de não representação mimética, o faz por meio também da figura do autor da obra, nesse caso, personificado no artista Arariboia. A temática que apareceu com maior vigor em parcela considerável da produção de Lísias, reconhecida formalmente como auto ficcional, pode ser abstraída também nesse livro, contudo em um outro formato. A ideia de presença e ausência do artista (autor) se constitui em ponto fundamental da obra. Uma de suas passagens pode ser compreendida seguindo essa direção, em "que Arariboia afirma não ser um cadáver e se recusa a cobrir o corpo nu" (LÍSIAS, 2016a, p. 19), como relata o resumo preambular do capítulo dois. Em artigo, Pedro Monteiro compara, nesse episódio, José de Arariboia a José de Arimateia.

José de Arariboia, o "nosso herói”, é uma espécie de José de Arimateia esvaziado de qualquer lenda. A diferença é que este Zé carioca e contemporâneo não guarda o corpo santo para a posteridade. $\mathrm{Na}$ verdade, a transcendência é para ele matéria tão inalcançável quanto desinteressante. (MONTEIRO, 2017, p. 233)

É relevante a ideia da importância dada ao corpo e à imanência em oposição à transcendência. Isso diz muito da perspectiva da arte contemporânea de se mesclar 
indissociavelmente à vida. Contudo, julgamos também que, mais que uma presença do corpo, pode-se reconhecer que o autor, na figura do artista, não morreu ou efetivamente não desapareceu. Ao contrário, a auto exposição de Arariboia e seu acolhimento pelo público reforçam a concepção de que o autor ressurge, enquanto um elemento indispensável. Enfatizo, assim como Klinger, que seu retorno se dá de uma forma problematizada, ""uma construção que certamente se afasta do paradigma romântico de gênio e inspiração, que ainda hoje se sustenta na figura de muitos escritores" (KLINGER, 2012, p. 56).

Quando Klinger propõe a performance como processo constitutivo da auto ficção, compreende-se que, apesar de ressurgir como elemento da vida factual, o autor retorna também como instância necessária que vai um pouco além do texto literário. Em sua proposta teórica para a noção de performance, Klinger se utiliza, dentre outros, do conceito de Richard Schechner que a identifica como operação que está presente não apenas na arte, mas em várias situações da vida cotidiana, antes de tudo. "Performances artísticas, rituais ou cotidianas - são todas feitas de comportamentos duplamente exercidos, comportamentos restaurados, ações performadas que as pessoas treinam para desempenhar, que têm que repetir e ensaiar." (SCHECHNER, 2003, p.27). Assim, pode-se entender o uso artístico da performance como uma operação de "semiotização", como denomina Paul Zumthor, de um contexto específico, isto é, transformar "em ficção aquilo que parecia ressaltar do cotidiano" (ZUMTHOR, 2002, p. 41). Como nos salienta Schechner, qualquer evento pode, dessa maneira, ser analisado como performance. E esse tem sido o trabalho central da arte desde Duchamp, ou seja, o deslocamento dos significados como forma de relativização do processo que se dá na própria arte.

Trilhando o caminho apontado por Schechner, é possível inferir que a arte, na era estética, de uma maneira geral significa operar com performance. Ressaltando que no sistema chamado por Rancière de regime estético, essas ações artísticas são planejadas de forma a refletir sobre a própria arte (RANCIÈRE, 2009).

\footnotetext{
Tratar qualquer objeto, obra ou produto como performance - uma pintura, um romance, um sapato, ou qualquer outra coisa - significa investigar o que esta coisa faz, como interage com outros objetos e seres, e como se relaciona com outros objetos e seres. Performances existem apenas como ações, interações e relacionamentos. (SCHECHNER, 2003, p. 28-29)
}

Assim como Klinger, Schechner também demonstra que o ser, a ação, o mostrarse fazendo e todas demais categorias enquadradas naquilo que se nomeou por performance, evidenciam uma dupla natureza nos elementos cotidianos - que são absorvidos e ressignificados na arte. Por um lado, existe neles um caráter ritualístico, repetitivo e diríamos mesmo artificial, no sentido da sedimentação exercida pela cultura. Por outro, reconhece-se em cada evento uma ação única que não se repete, em parte porque é uma intersecção de inúmeros elementos que, devido à imprevisibilidade não pode ser imitada. E, na mesma medida, é pela interatividade que esse ato é gerado por meio da semiotização que o público exerce, sendo que cada espectador, ainda que seguindo uma tendência de significação, estabelece um sentido que é ao mesmo tempo único. E é nesse espaço entre o coletivo e a transgressão da norma que a subjetividade se apresenta. Consideramos que, por essa razão, a arte performática seja tão produtiva na discussão da subjetividade enquanto conceito e da política no sentido da relação entre o indivíduo e os modos de ser e fazer coletivos.

Por isso, também encontramos na performance, enquanto conceito, a constatação tão presente na arte contemporânea do espectador também exercendo o papel de autor, 
bem como a concepção de que autoria é, em grande medida, compartilhada. Como frisa Schechner, a "maioria das performances, cotidianas ou não, têm mais de um autor. Rituais, jogos e performances da vida diária são escritas por um ente coletivo Anônimo ou pela Tradição" (SCHECHNER, 2003, p.34). É nessa tensão entre o autor que assina a obra e sua criação coletiva que também trabalha a arte e a literaturas atuais. É interessante retomar dois elementos presentes em A vista particular. Um deles está no happening e nas performances que são elaboradas discursivamente dentro da trama. Como vimos, nesses eventos, é difícil apontar Arariboia como o criador do contexto que se perfaz em arte. Ainda que ele assuma a autoria e se celebrize por isso, é na interação com os outros diversos espectadores que o evento ganha corpo e significados. A autoria do protagonista, que é a que se publiciza, seria uma entre outras incontáveis em meio à recepção que não são dadas à mostra. $\mathrm{O}$ outro componente da trama é o que simula a criação da história pela voz de um narrador que poderia muito bem ser confundido com o autor, compartilhando, contudo, essa narração com uma segunda voz que abre os capítulos. É interessante observar a tensão e mesmo o conflito que se estabelece entre esses dois narradores - ou autores fictícios - em função do espaço ocupado por cada um deles na trama. Em dados momentos, o segundo narrador se queixa ao leitor por ter sido sua função reduzida por imposição do narrador principal. E em outros, este último se queixa do outro quanto à antecipação de episódios da trama. Assim, esse conflito entre narradores pode ser relevante para mostrar que, embora realizada de maneira coletiva, a arte, mesmo na contemporaneidade, sempre é constituída como arte tendo como ponto de partida um sujeito que assume a autoria. Mesmo porque, como vimos, ela é sempre fruto de elaboração conceitual prévia. Mas ela, a autoria, pode ser também encarada como um "se mostrar autor", isto é, como uma perfomatização do sujeito autor, como um personagem.

É assim que entendemos o conceito de auto ficção como performance proposto por Klinger. Ou seja, restauração de comportamentos e eventos que dizem respeito ao autor, enquanto sujeito dentro e fora da obra, sendo ele mesmo o principal ator dessa performance. Em nossa acepção, consideramos, todavia, que ela não necessariamente precisaria se vincular a uma obra rotulada como autoficcional ou autobiográfica. A auto ficção seria, assim, encarada como uma espécie particular de performance que está quase sempre presente na arte e evidencia a importância do papel do autor. Um desses "eus" que faz parte de todo esse conjunto do cotidiano do artista e do escritor é aquele que se conforma em ações que podem ser entendidas como performance. Mas, ainda que ele seja o principal ator, ou autor, nessa encenação e elaboração de si, ele tem a consciência, enquanto artista, da participação do espectador na criação da performance. Ou das performances, já que são várias dentro de uma. A cada leitura ou apreciação, um sentido específico, ainda que pouco diverso, sempre está emergindo.

Além de se elaborar enquanto escritor e artista, Lísias parece encenar uma condição que, ao mesmo tempo questiona e satiriza essa configuração da arte contemporânea nascida desse dilema entre o autor que propõe a obra e a autoria do espectador. Dilema este que é ao mesmo tempo a própria matéria dessa arte que, como dissemos, não tenta representar por imitação, mas trabalha com a própria ideia da diversidade de significados que se perfazem em cada contexto coletivo e subjetivo. Proponho, portanto, que Lísias também se utiliza conceitualmente dessa ideia do impasse vivenciado pelo artista contemporâneo para se elaborar enquanto um personagem de si. Ou, para assumir o papel duplo de ator e personagem e que nesse caso atende, de uma forma geral, ao mito do artista contemporâneo. Essa proposição reitera e mantém diálogo com a concepção acerca da auto ficção, como forma de criação de um "mito do escritor"” (KLINGER, 2012, p. 45). Nesse caso, a personagem 
e autor Ricardo Lísias, que se performatiza, corresponde também a um conceito ou modelo do artista, se levarmos em consideração certas reflexões de Duchamp a respeito do ato criador, as quais iremos delimitar logo mais. E ao mesmo tempo aponta para $A$ vista particular como eco dessa performance do artista que não tem controle sobre as significações possíveis impostas à sua obra, pelos espectadores dela.

Integrando um projeto do Itaú Cultural, intitulado "Encontros de Interrogação", em novembro de 2015, durante o "Encontro Conexões", Ricardo Lísias concedeu uma espécie de vídeo-entrevista. Segundo o Canal do Itaú Cultural, respaldando-se naquilo que é relatado nesse depoimento, Lísias "explica seu interesse pela ficção literária e comenta sua produção atual [e] da crise que vive com sua escrita no momento da gravação, pois constata diferenças entre a reflexão sobre cada projeto antes da produção e o que se revela de fato após a publicação" (LİSIAS, 2016b). De fato, o que norteia o projeto do Itaú Cultural é convocar cada autor e escritor envolvido a realizar um depoimento a respeito de como enxerga sua própria obra, seus propósitos e assim, se autorrelatar. Em sua breve fala sobre si, Lísias inicia se autodescrevendo como "pesquisador atualmente" e escritor. Segue recapitulando elementos de sua infância e genealogia que explicariam o seu gosto pela literatura e também pelas artes, acompanhando uma tradição familiar. Até aí nada de mais, ainda que só esse "se mostrar" constitua uma espécie de escrita de si performática, vez que exista ou não correspondência entre o dito e os fatos vivenciados, é uma auto elaboração apresentada. Contudo, o que mais chama a atenção é a dita crise, produto de uma frequente desconformidade entre a reflexão prévia de Lísias a respeito do propósito de um trabalho e a maneira como foi apreciado e entendido pelo público. Dentre outras coisas, diz o escritor: "Eu achava que meus textos focavam em um alvo e eles acabam acertando em outros também. Atualmente eu me sinto um pouco perdido com relação ao que eu tenho feito" (LÍSIAS, 2016b). Isso para explicar qual é sua proposta literária, e segue dizendo estar vinculada a um intenso trabalho com o discurso e a linguagem visando a intervir, por meio delas, em outras diversas instâncias.

O que nos deixa nítida a performance, que atinge mesmo um tom satírico, é o fato de que as obras são planejadas. Fica implícito que, na relação com o espectador, outros alvos serão atingidos inelutavelmente. $O$ que se aspira no esquema da arte contemporânea é justamente que o inesperado tenha o seu lugar na autoria que é assumida também por aqueles na condição de espectador. A possível surpresa manifesta por Lísias logra, velada e dissimuladamente, a apresentação de si como um artista contemporâneo conceitual, que não se reconhece inteiramente como tal. Nessa perspectiva Lísias constantemente se avizinha do protagonista de A vista particular e dos outros artistas participantes do regime estético, principalmente os contemporâneos. Por essa razão aludimos ao célebre texto de Duchamp "O ato criador" (DUCHAMP, 1975) em que ele reflete sobre essas possíveis divergências de significação entre a proposta do artista e aquilo no que se converte a obra diante da recepção.

Em "O ato criador", Duchamp começa definindo o artista em sua ação como um ser mediúnico, isto é, alguém que apesar de ter alguma intenção consciente, em maior medida é inconsciente do que está executando com relação aos motivos e ainda mais, aos resultados.

Ao darmos ao artista os atributos de um médium, temos de negar-lhe um estado de consciência no plano estético sobre o que está fazendo, ou por que está fazendo. Todas as decisões relativas à execução artística do seu trabalho permanecem no domínio da pura intuição e não podem ser objetivadas numa autoanálise, falada, escrita ou mesmo pensada. (DUCHAMP, 1975, p. 72) 
Ao conferir a uma elaboração o status de arte, o artista age com alguma intenção, mas sua subjetividade atua principalmente por processos inconscientes, de forma tal que, para Duchamp, na interação com o público, o resultado da recepção sempre há de divergir, em maior ou menor grau, do significado inicial que se atribuía a essa obra. E mais ainda, o artista nunca tem consciência dessa diferença que se estabelece no ato criador entre sua proposta e a interação que se estabelece com o espectador.

\begin{abstract}
O resultado desse conflito é uma diferença entre a intenção e a sua realização, uma diferença de que o artista não tem consciência.

Por conseguinte, na cadeia de reações que acompanham o ato criador falta um elo. Esta falha que representa a inabilidade do artista em expressar integralmente a sua intenção; esta diferença entre o que quis realizar e o que na verdade realizou é o "coeficiente artístico" pessoal contido na sua obra de arte. Em outras palavras, o "coeficiente artístico" pessoal é como uma relação aritmética entre o que permanece inexpresso embora intencionado, e o que é expresso não intencionalmente. (DUCHAMP, 1975, p. 73)
\end{abstract}

O que Duchamp demonstra é a que ponto essa imprecisão de sentidos na relação entre a ação do artista, sua intenção e a operação do público determinando a qualidade e os significados do trabalho, é a própria matéria da arte contemporânea. Assim, Lísias, de fato, não está incorrendo em erro ao apontar que existe uma disparidade entre o que ele pensava para suas obras e a forma como elas se constituíram na relação com o público. Mas por considerarmos, que, embora não tenha a capacidade de atuar de forma plenamente consciente, racional e precisa na expressão de suas intenções em um "ato criador", Lísias, assim como Duchamp, ou qualquer outro artista contemporâneo, está ciente desse processo. Afinal como dissemos a arte contemporânea tem como marca a constatação de que ela se constitui como um procedimento não mimético, que depende da interação com o público. Observemos, por exemplo, que, o fenômeno também presente na ideia de que a linguagem é imprecisa na representação dos fatos, foi diversas vezes usado como autodefesa por Lísias, diante das reações controversas do público.

Queremos, dessa forma, evidenciar que Lísias, mais do que se sentir perdido em relação as suas intenções, tem atuado - nas duas principais acepções do termo - no sentido de construir performaticamente a si mesmo, enquanto um personagem que corresponde ao mesmo tempo ao artista contemporâneo. Um artista que caminha numa direção, mas que impreterivelmente alcançará um destino que não corresponde precisamente ao planejado. Assim como observamos na atuação de Arariboia, que, deslocando a favela, do seu significado comum, a instituiu como uma grande composição de arte e posteriormente perde seu controle no desenrolar dessa obra. O que por vezes parece ser duvidoso, mas entendemos que pode ser também encarado como uma performance dentro da performance auto ficcional, é essa pretensa ingenuidade, carregada, ao contrário, de grande dose de ironia, ao se dizer perdido e surpreso com os resultados assumidos por um livro ou experimento literário. Essa ambiguidade é difícil de ser superada, pois como vimos no primeiro capítulo, a arte contemporânea é, ao mesmo tempo, esse processo de deslocamento e reflexão sobre o próprio sistema de artes, e também divulgação de si mesma.

Para tanto, a tensão que se promove na indecisão quanto aos significados e a crítica irônica do próprio sistema é um elemento essencialmente constitutivo dessa arte. Como vimos, no caso do Souzousareta Geijutsuka de Yuri Firmneza, que impunha uma crítica satírica à imprensa e ao mesmo tempo, ao sistema das artes, criando um artista imaginário que teria maior autoridade e reconhecimento, nos moldes do que fez também 
Duchamp com seus ready-mades e pseudônimos. Essa maneira de tencionar que a arte contemporânea instituiu para promover a reflexão trabalha quase sempre com o escárnio e a exposição do ridículo das instituições. Afirma, por exemplo, Janis Mink, em seu livro sobre Duchamp, que os ready-mades, apesar de, ao longo do tempo, assumirem cada qual uma identidade própria "foram quase sempre uma referência autobiográfica; contudo o elemento humor foi-se tornando ainda mais forte" (MINK, 2006, p. 63). Em que pese essa referência fosse velada, sendo seu significado original dificilmente recuperado.

Em Divórcio (Alfaguara, 2013), o que se estabelece é algo parecido, embora por um processo aparentemente inverso, onde toda a intimidade parece estar exposta. Não se sabe, de fato, o que se sucedeu na vida privada do escritor Ricardo Lísias, embora a configuração discursiva de que ele se utiliza crie a ilusão de que seria a obra uma narração de memórias de um evento traumático recente em sua vida. Sendo possível ou não estabelecer a confirmação ou negação da maioria dos fatos narrados, esse foi o grande triunfo alcançado pela obra. Grande parte de seus espectadores instituíram um significado subjetivamente, sempre oscilando entre as polaridades do puramente factual ou ficcional, defendendo em absoluto como verdade uma dessas duas perspectivas. Assim, o livro também trata da ação da opinião pública e é impossível chegar ao sujeito Ricardo Lísias verdadeiro através dela, considerando que existisse um. Mas ela contribuiu para a elaboração do artista e autor Ricardo Lísias, visto que esse impasse na verificação dos sentidos autênticos provocou polêmica generalizada. É curioso que, tendo ou não convertido um episódio factual de sua vida em peça de arte, Lísias não tem por hábito expor sua privacidade nas redes sociais, ou em entrevistas e relatos. Mink, descreve algo semelhante na trajetória de Duchamp. "Apesar de a obra, devido à sua natureza artisticamente provocatória, ter recebido uma enorme atenção crítica, a sua vida esteve envolta na famosa "parede de silêncio" de Duchamp" (MINK, 2006, p.7). Assim, o mito Duchamp que se conhece não é o dos elementos autobiográficos que são deslocados para significados diversos dos originais a cada obra. Da mesma maneira, o Ricardo Lísias auto ficcional, é o artista que se realiza como performance em obras, entrevistas, aparições em redes sociais. Mas não é nem o Lísias em sua vida íntima factual e nem mesmo o correspondente aos personagens de Divórcio e o Céu dos suicidas. E simultaneamente é todos eles.

Assim como Arariboia se transforma e se descontrói seguindo as mudanças alcançadas por sua obra a cada deslocamento, sendo que sua ausência o faz ainda mais presente, assim também é Lísias em A vista particular. Ele está presente no jogo entre experimentações artísticas de Arariboia e recepção do público que reportam às polêmicas suscitadas por seus empreendimentos que fundiram ficção e fatualidade. Curiosamente parece que a recepção, de maneira geral, não se atentou para essa marca. Ironicamente, podemos notar que na capa do livro que o nome de "Ricardo Lísias", isto é, a assinatura da obra, vem logo abaixo do título, com dimensões consideravelmente maiores, ganhando destaque desmesurado. Lísias parece mesmo brincar com a proposição que diz que "o sujeito que escreve despista todos os signos de sua individualidade particular; a marca do escritor não é mais do que a singularidade de sua ausência; é preciso que ele faça o papel do morto no jogo da escrita" (FOUCAULT, 2006, p.269).

Esse autor-personagem de entrevistas e redes sociais é também aquele que se instaura na ausência dos outros Lísias. Isso porque a necessidade da presença do autor por parte do público faz tomá-lo por verdadeiro. E ele o é, mas apenas no momento de sua aparição, como dissemos num ato de performance. Ainda que sejam vários Lísias, se assim podemos dizer, um vai se construindo no imaginário popular, enquanto 
personalidade do cenário literário e artístico que vai se materializando na concatenação dessa série de obras polêmicas e na interação com o espectador.

No relato concedido ao Encontros de Interrogação do Itaú Cultural, o qual mencionamos, Lísias narra uma sucessão de propostas e intenções iniciais das obras e a descoberta posterior de um sentido principal diverso na relação com o espectador. Divórcio seria um livro sobre a ética no jornalismo cultural, mas, para o autor se converteu em uma obra sobre despolitização e violência da boataria. Posteriormente ele elabora em conjunto com o público, por meio de uma página do Facebook, a série de histórias curtas Delegado Tobias, que seria um trabalho sobre boatos, inclusive da utilização deles na criação, segundo Lísias, mas se converteu, na verdade, em uma obra sobre a precariedade das instituições brasileiras. Isso por que, foi aberto um inquérito contra o escritor, fruto de uma denúncia anônima ao Ministério Público, por falsificação de documentos. O que que havia na obra, na verdade, eram composições de design visual imitando peças processuais. Muitas pessoas, até mesmo do meio literário e acadêmico, levantam a possibilidade de não ter havido processo ou ter sido o próprio Lísias a se autodenunciar. Julian Fuks, por exemplo, em uma mesa de debates sobre auto ficção, com Lísias, no SESC Minas Gerais, em 11 de abril de 2017, questiona - em tom de brincadeira, é verdade - se o experimento não teria continuado. Diz Fuks: "A suspeita é que de fato você tenha, de fato, protocolado uma acusação contra si mesmo" (FUKS, 2017). Com efeito, ocorre que a justiça aceitou realmente a denúncia e levou o processo adiante.

Sejam fruto de coincidências ou de ardiloso planejamento, os experimentos de Lísias têm quase sempre encontrado um êxito surpreendente. Talvez contribua para isso esse jogo entre o sentido atribuído para uma obra pela recepção, sendo posteriormente usado mote para o próximo projeto. Quando Lísias abstrai um dos sentidos possíveis, posteriormente e o generaliza, como dizer que o experimento o Delegado Tobias falava, mais do que outra coisa, sobre a precariedade das instituições brasileiras, ele está reassumindo a autoria dessa obra, ainda que pegando por empréstimo o sentido que parte do público lhe atribuiu. E ao mesmo tempo, ele constrói uma narrativa em que a sua vida pública, naquilo que tange aos trabalhos desenvolvidos, se coordena de forma tal que somos levados a encará-lo como um artista contemporâneo que perde o controle sobre suas criações que tomaram vida própria. Observada posteriormente, pelo próprio autor, essa narrativa simula uma coerência tão precisa que nos leva inclusive a questionar, assim como Fuks, o que foi planejado ou não. E assim ele instituiu admiravelmente uma grande auto ficção extratextual com base na performance. Tal qual o conceito de simulação de Baudrillard, ela é uma realidade verdadeira, mas apenas no momento em que acontece, assim como o happening. Arariboia é, por conseguinte, um personagem que encarna esse processo. A alegação de não ter culpa, pois é isso que ele diz nesse último debate citado e em várias outras entrevistas, embora seja verdadeira sobre certo ângulo, só confirma a sua forma de atuar. Isto é, além de colocar em cheque a veracidade dos fatos, através da ficção, ele a utiliza para a composição da verdade de sua vida pública enquanto artista. Nesse sentido, Fuks diz algo interessante sobre Lísias, naquele mesmo debate.

Isso me faz repensar a declaração que eu tinha dado aqui de que nos livros do Lísias se entra numa vertigem imaginosa que vai se afastando de uma interpretação possível da vida e da realidade, se aproximando de uma percepção clara do ficcional. O caso é que a vida do Lísias faz esse movimento, não é a obra (FUKS, 2017). 
Embora haja um certo humor nesse trecho de Fuks, consideramos que os dois movimentos acontecem, de fato e simultaneamente. Sua vida pública se constitui também em sua obra, sendo pertinente apontar o seu caráter ficcional. E decerto não totalmente à revelia do escritor. No entrelaçamento entre vida e operações comunicativas que vão para além da arte, Lísias se mostra consciente desses processos e os utiliza tanto para criticá-los como para se estabelecer como essa personagem pública reconhecida. Evidentemente, o êxito obtido é também fruto de grande habilidade discursiva, tanto no espaço interno dos livros quanto no extraliterário.

A auto ficção de Lísias, reafirmamos, se opera de uma forma similar ao que apresentamos com o caso de Souzousareta Geijutsuka. Com a diferença que o artista Ricardo Lísias é uma personagem de carne e osso. O principal mérito de sua obra na discussão do aspecto político está muito mais em desestabilizar a fronteira entre o ficcional e o factual levando a dúvida para o espectador, que assim tem ao menos o benefício da dúvida ao optar por uma significação. E ao mesmo tempo tem a consciência de que não existe verdade e nem mesmo verdadeira escolha. Muito mais do que as temáticas reconhecidas pelo próprio autor no cerne de suas obras. Como por exemplo, quando diz que Divórcio trata das falhas éticas existentes no trabalho da imprensa. Assim como nas artes plásticas e visuais contemporâneas, este livro concede ao espectador condição de coautoria e de refletir sobre ela. E mais que isso, consciência de que a incerteza que existe na esfera das artes é a marca sensível de aspectos que a ultrapassam, isto é, das relações políticas do nosso tempo.

Ainda que admitindo a intencionalidade do artista, Lísias, na execução da obra e na sua performação enquanto uma personagem que corresponde a um autor celebrizado, é necessário observar que a sua ação é limitada pela indeterminação vivenciada na recepção do espectador em relação à obra. $\mathrm{O}$ autor, nesse caso e quase sempre, no mesmo momento que é presente e dirige a amplitude de significados a partir da obra, e de si como auto personagem, se estabelece também na sua ausência e no jogo com o espectador. Ele se conforma nesse interstício

Em sua análise da "morte do autor" e da reconhecida aporia presente nessa asserção, Gorgio Agamben propõe que também a autoria se estabelece nesse jogo entre a autoridade e o testemunhar da presença-ausência do autor pelo espectador. Assim como a subjetividade se mostra, ou se coloca em jogo, como diz Agamben, nessa interação, da mesma maneira o autor se estabelece nesse encontro que escolhemos entender como uma performance.

O sujeito - assim como o autor, como a vida dos homens infames — não é algo que possa ser alcançado diretamente como uma realidade substancial presente em algum lugar; pelo contrário, ele é o que resulta do encontro e do corpo-a-corpo com os dispositivos em que foi posto - se pôs - em jogo. Isso porque também a escritura — toda escritura, e não só a dos chanceleres do arquivo da infâmia - é um dispositivo, e a história dos homens talvez não seja nada mais que um incessante corpo-a-corpo com os dispositivos que eles mesmos produziram - antes de qualquer outro, a linguagem. (AGAMBEN, 2012, p. 63)

A grande virtude e engenhosidade que podemos destacar no jogo que Lísias realiza em sua auto ficção extraliterária talvez seja o reconhecimento de que assim se dá também no mundo factual a elaboração da subjetividade. E assim, se utilizar dela, nos limites que lhe são impostos para se estabelecer como uma figura pública reconhecida, mas também para fazer emergir tensões que movem a sua obra. 
ABSTRACT: In his work, Ricardo Lísias was noted for the writing of controversial autofictions because of the ambiguities involved in this literary process. In A vista particular (Alfaguara, 2016), it encounters a plot whose protagonist is an artist who also uses mechanisms of contemporary antimimetic art. The extreme and even surreal actions of this character can be analyzed as a means of understanding the proposal of Lísias in his works, as well as the author inscribes performatically as a character of himself, making his public life indistinct from his work.

Keywords: Literature. Contemporary art. Ricardo Lísias. Authorship. Autofiction. Performance

\footnotetext{
* Professor Adjunto do Departamento de Letras da UFSJ. Doutor em Estudos Literários - Subárea Literatura Comparada - pela UFMG.

** Mestrando em Letras vinculado ao Programa de Pós-Graduação em Letras da Universidade Federal de São João del-Rei

${ }^{1}$ A história por trás da foto do menino que chocou o mundo. Publicação: 5 set. 2015. Disponível em: $<$ https://www.terra.com.br/noticias/mundo/asia/a-historia-por-tras-da-foto-do-menino-sirio-que-chocouo-mundo,a491948f737fabaedc2b65294952c1d8zbulRCRD.html>. Acesso em: 29 de abr. 2017.
}

\section{REFERÊNCIAS}

AGAMBEN, Giorgio. Profanações. São Paulo: Boitempo, 2012.

BAUDRILLARD. Simulacros e simulação. Lisboa: Relógio D'água, 1991.

DUCHAMP, Marcel. O ato criador. In: BATTCOCK, Gregory (org.). A nova arte. São Paulo: Ed. Perspectiva, col. Debates, 1975.

FIRMEZA, Yuri. Declarações dadas no debate realizado Centro Dragão do Mar. 11 ago. 2006. In: SABÓIA, Ricardo. Adorável invasor. Overmundo. Publicação: 13 jan. 2006. Disponível em: < http://www.overmundo.com.br/overblog/adoravel-invasor> Acesso: 02 abr. 2017.

FOUCAULT, Michel. O que é um autor? In: Ditos e escritos III: Estética: literatura e pintura, música e cinema. 7.ed. Rio de Janeiro: Forense, 2006.

FUKS, Julián. Literaturas: Auto ficção na Literatura Brasileira Contemporânea - Julián Fuks, Ricardo Lísias e Manuel da Costa Pinto. Sesc Minas Gerais. 11 abr. 2017. Publicção: 29 mai. 2017. Disponível em: <https://www.youtube.com/watch?v=lmwNbW3Kkzg> Acesso: 13 abr. 2017.

LÍSIAS, Ricardo. A vista particular. Rio de Janeiro: Alfaguara, 2016a.

Divórcio. Rio de Janeiro: Alfaguara, 2013.

$\begin{array}{cccccc} & \text { Entrevista concedida ao Itaú Cultural. Ricardo Lísias } & \text { Encontros de Interrogação } \\ \text { (2015). } & \text { Publicação: } & 26 & \text { fev. } & 2016 \mathrm{~b} . & \text { Disponível } \\ \text { em: }\end{array}$ <https://www.youtube.com/watch?v=17r0f6UgSbo>. Acesso em: 29 de abr. 2017.

KLINGER, Diana. Escritas de si, escritas do outro: o retorno do autor e a virada etnográfica. 3. ed. Rio de Janeiro: 7 Letras, 2012.

MARTINS, Nardélia. Revista Famecos, Porto Alegre, v. 18, n. 2, p. 408-430, maio/ago. 2011. e-ISSN: 1980-3729

MINK, Janis. Marcel Duchamp: 1887-1968: A arte como contra-ataque. Koln: Taschen, 2006. 
MONTEIRO, Pedro Meira. A vista particular, de Ricardo Lísias (resenha). ARS - Revista do Programa de Pós-Graduação em Artes Visuais da ECA-USP, São Paulo. v.15, n.29, 2017. ISSN 2178-0447.

MOURA, Dalwton. Souzousareta; Arte, natureza e tecnologia. Diário do Nordeste. Publicação: 10 jan. 2006. Disponível em: <http://diariodonordeste.verdesmares.com.br/cadernos/caderno3/arte-natureza-e-tecnologia-1.574602> Acesso: 02 abr. 2017.

PELED, Yiftah. Performance na contemporaneidade. ARS - Revista do Programa de PósGraduação em Artes Visuais da ECA-USP, São Paulo. v. 10, n. 19, 2012. ISSN 2178-0447.

RANCIÈRE, Jacques. A partilha do sensível: estética e política. 2.ed. São Paulo: Editora . 34, 2009.

SCHECHNER, Richard. O que é performance? Trad. Dandara. Rio de Janeiro, Revista de Teatro, crítica e estética: O Percevejo, UNIRIO, v. 11, n. 12, 2003. ISSN 0104-7671

ZUMTHOR, Paul. Performance, recepção e leitura. 2. ed. São Paulo: Cosac Naify, 2002. 